\title{
Ambulatory teaching: Do approaches to learning predict the site and preceptor characteristics valued by clerks and residents in the ambulatory setting?
}

\author{
M Dianne Delva* ${ }^{* 1}$, Karen W Schultz ${ }^{\dagger 1}$, John R Kirby ${ }^{\dagger 2}$ and \\ Marshall Godwin ${ }^{\dagger 1}$
}

Address: ${ }^{1}$ Department of Family Medicine, Queen's University, Kingston, Ontario, Canada and ${ }^{2}$ Faculty of Education, Queen's University, Kingston, Ontario, Canada

Email: M Dianne Delva* - mdd2@post.queensu.ca; Karen W Schultz - kws@post.queensu.ca; John R Kirby - kirbyj@educ.queensu.ca; Marshall Godwin - godwinm@post.queensu.ca

* Corresponding author †Equal contributors

Published: 14 October 2005

BMC Medical Education 2005, 5:35 doi:10.1186/1472-6920-5-35
Received: 0I June 2005

Accepted: 14 October 2005

This article is available from: http://www.biomedcentral.com/1472-6920/5/35

(c) 2005 Delva et al; licensee BioMed Central Ltd.

This is an Open Access article distributed under the terms of the Creative Commons Attribution License (http://creativecommons.org/licenses/by/2.0), which permits unrestricted use, distribution, and reproduction in any medium, provided the original work is properly cited.

\begin{abstract}
Background: In a study to determine the site and preceptor characteristics most valued by clerks and residents in the ambulatory setting we wished to confirm whether these would support effective learning. The deep approach to learning is thought to be more effective for learning than surface approaches. In this study we determined how the approaches to learning of clerks and residents predicted the valued site and preceptor characteristics in the ambulatory setting.
\end{abstract}

Methods: Postal survey of all medical residents and clerks in training in Ontario determining the site and preceptor characteristics most valued in the ambulatory setting. Participants also completed the Workplace Learning questionnaire that includes 3 approaches to learning scales and 3 workplace climate scales. Multiple regression analysis was used to predict the preferred site and preceptor characteristics as the dependent variables by the average scores of the approaches to learning and perception of workplace climate scales as the independent variables.

Results: There were 1642 respondents, yielding a 47.3\% response rate. Factor analysis revealed 7 preceptor characteristics and 6 site characteristics valued in the ambulatory setting. The Deep approach to learning scale predicted all of the learners' preferred preceptor characteristics $(\beta=0.076$ to $\beta=0.234, p<.00 \mathrm{I})$. Valuing preceptor Direction was more strongly associated with the Surface Rational approach $(\beta=.252, p<.001)$ and with the Surface Disorganized approach to learning $(\beta=.154, p<00$ I) than with the Deep approach.

The Deep approach to learning scale predicted valued site characteristics of Office Management, Patient Logistics, Objectives and Preceptor Interaction $(\mathrm{p}<.00 \mathrm{I})$. The Surface Rational approach to learning predicted valuing Learning Resources and Clinic Set-up $(\beta=.09, p=.00 \mathrm{I} ; \beta=.197, \mathrm{p}<.00 \mathrm{I})$. The Surface Disorganized approach to learning weakly negatively predicted Patient Logistics $(\beta=-.082, p=.003)$ and positively the Learning Resources $(\beta=.088, p=.003)$.

Climate factors were not strongly predictive for any studied characteristics. Role Modeling and Patient Logistics were predicted by Supportive Receptive climate $(\beta=.135, p<.001, \beta=.118, p<.001)$.

Conclusion: Most site and preceptor characteristics valued by clerks and residents were predicted by their Deep approach to learning scores. Some characteristics reflecting the need for good organization and clear direction are predicted by learners' scores on less effective approaches to learning. 


\section{Background}

Medical care is increasingly delivered in the ambulatory care setting. Since learning in context improves learning it is appropriate and necessary that medical training occurs in the future practice setting [1,2]. Teachers must organize the setting and approach teaching in this context in order to maximize learning.

We developed a survey instrument to assess the site and preceptor characteristics that clerks and residents believe to be most valuable to their learning in the ambulatory setting using validated questionnaires and study group consensus [3]. Many items such as giving feedback and discussing clinical reasoning were valued by most learners, although there were some differences for learners from different specialties or at different training levels. A few site and preceptor characteristics, such as teaching in the patient's presence, thought to be important for learning were not valued. Learner preferences may be appropriate guides for teaching, but it is not clear that these preferences always support effective learning. Studies in higher education suggest that the approach to learning affects learning outcomes. The conceptual models of approaches to learning include both motivation for learning and the strategies to fulfill the motivation and are influenced by the context for learning. It is widely accepted that the deep approach to learning which includes an integrative approach to understanding, leads to improved learning outcomes while surface (or reproducing) approaches which depend on rote memorization, are less effective [4]. Learners adopting surface approaches to learning may prefer site and preceptor characteristics that support their surface learning; instructors who follow those preferences may inadvertently undermine their own teaching!

Bowen and Irby, reviewed the quality and costs of education in the ambulatory setting and described what is known and the gaps in our knowledge [5]. Many studies have been conducted in single institutions and in the traditional ambulatory specialties. Bowen and Irby suggest that a conceptual model examining the teacher-learnersetting framework is needed to understand the effectiveness of the ambulatory setting for learning.

Challenges in examining the effectiveness of a learning environment include the reliability of the evaluation method, confounding factors and the ability to generalize beyond single groups or institutions. One way to examine the complex interaction of the environment and the approach taken by learners in that environment is by measuring the approaches to learning in the workplace [6].
The approach to learning, course perceptions and personal factors are known to interact to affect undergraduate learning [7-11]. Course demands influence university students to adopt surface, deep, or achieving approaches to learning. A deep approach to learning is motivated by an intrinsic desire for learning and involves strategies to form an integrated and personal understanding. In contrast, the surface approach to learning is motivated by fear of failure and is associated with rote memorization and a perception of heavy workload demands in the course. In studies of practicing physicians and clinical trainees (clerks and residents) we confirmed that perception of the workplace climate is associated with the approach to learning $[12,13]$. Perceptions of heavy workload are associated with surface disorganized approaches to learning (figure 1). A deep approach to learning is associated with perceptions of choice and independence and a supportive, receptive workplace climate (figure 1).

Our assumption in this study was that a deep approach to learning could be viewed as a surrogate for more effective learning and that a surface disorganized approach was less effective in most circumstances. Students who adopt a deep approach to learning may value characteristics of the learning environment and teaching that support this approach which differ from students who adopt less effective approaches to learning. It would seem appropriate then for teachers to attend to those site and preceptor characteristics that support a deep approach to learning. The purpose of this study was to answer the question: Do approaches to learning and perception of the workplace climate predict the site and preceptor characteristics valued by clerkship students and residents in the ambulatory setting?

\section{Methods}

All medical clerks $(n=532)$ and residents $(n=2939)$ at the five medical schools in Ontario were invited to respond to a survey regarding the site and preceptor characteristics most valued in the ambulatory setting and to complete the Workplace Learning Questionnaire. The study was approved by the Queen's University Research Ethics Board.

Students rated 24 site characteristics and 38 preceptor behaviours on a Likert scale from 1 (very important for learning) to 5 (not at all important for learning) or D (detrimental for learning). (sample items in Table 1) The Workplace Learning Questionnaire developed by Kirby and colleagues was modified to include reference to preceptors as well as supervisors [14] The questionnaire includes 30 items pertaining to approach to learning and 15 items pertaining to perception of workplace climate (Figure 1). Responses are made on a 5 point Likert scale, ranging from 1 (agree strongly) to 5 (disagree strongly). 


\title{
Definitions of Workplace Learning Factors
}

\author{
Approaches to work \\ Surface disorganized Feeling overwhelmed by work. (At work I find it difficult to
} organize my time effectively. Often I find I have to read things without having a chance to really understand them.)

Surface rational Preference for order, detail, and routine. (When I am given a job to do at work I like to be told precisely what is expected. When I learn something new at work I put a lot of effort into memorizing important facts.)

Deep approach Integrative approach that leads to personal understanding. (In trying to understand new ideas, I often try to relate them to real life situations to which they might apply. I find it helpful to "map out" a new topic for myself by seeing how the ideas fit together.)

\section{Workplace climate}

Choice-independence Perception of control over what one does and how one does it. (This organization gives you a chance to go about your work in ways which suit your own way of learning.)

Supportive-receptive Perception that help is available in the workplace and colleagues are understanding (The managers/supervisors in this organization always seem ready to give help and advice on the best way to learn something new.)

Workload Perception of heavy workload and having to cope alone (My job requires me to do too many different things.)

\section{Figure I}

Definitions of Workplace Learning Factors (sample items).

Questionnaires were mailed in bulk to the undergraduate and postgraduate medical schools and forwarded to all clerks and residents with addressed and stamped return envelopes. Responses were anonymous and a separate card was returned for entry into a draw for a personal digital assistant or equivalent monetary prize. An email reminder was sent four weeks later and follow up mailings were sent 8 and 20 weeks after the initial mailing.

Multiple regression analysis was used to predict the preferred site and preceptor characteristics as the dependent variables by the average scores of the approaches to learning and perception of workplace climate scales as the independent variables. Hierarchical modeling did not alter the results.

\section{Results}

Of the population surveyed, 1642 responded (47.3\%). Participants with $10 \%$ or more missing data (those who did not respond to items (54) and those who responded "not applicable" (27)) were excluded, leaving 1561 respondents for analysis. Missing values for the remaining participants were replaced with item means. The distribution of respondents was compared to the distribution of clerks and residents in Ontario. The proportions of women, junior residents, family medicine residents and 
Table I: Definitions of site and preceptor factors (sample items rated from most important to least important)

\begin{tabular}{|c|c|}
\hline Precptor Factor & Definition \\
\hline Professional Role Modeling & $\begin{array}{l}\text { Models professional behviours with staff and patients (Demonstrates effective interactions with } \\
\text { support staff) }\end{array}$ \\
\hline Teaching & Quality and efforts to provide good teaching (Discusses clinical topics in an organized way) \\
\hline Learning Climate & $\begin{array}{l}\text { Open and caring towards students and patients (Makes student feel like a valued member of the } \\
\text { practice) }\end{array}$ \\
\hline Feedback & The provision of timely and constructive feedback. (Gives constructive feedback) \\
\hline Direction & $\begin{array}{l}\text { Provides specific instruction on the student's role and is focused (Outlines specific task(s) to be done } \\
\text { during a clinical encounter) }\end{array}$ \\
\hline Patient Presence & Teaching with the patient present (Reviews case in the patient's presence) \\
\hline Health Care System Interaction & Preceptor teaches about resource use. (Teaches use of community resources) \\
\hline \multicolumn{2}{|l|}{ Site Characteristic Factor } \\
\hline Office Management & Teaching skills related to the running of a practice (Teaching of time management skills) \\
\hline Patient Logistics & $\begin{array}{l}\text { Opportunity to see a number and variety of patients (Opportunity to see an adequate number of } \\
\text { patients) }\end{array}$ \\
\hline Objectives & Defines and meets objectives (Clearly defined site objectives for the rotation) \\
\hline Learning Resources & Availability of resources in the clinic (Library resources available in the clinic) \\
\hline Clinic Set-up & Proximity and educational orientation of the clinic (Close proximity of clinic to campus) \\
\hline Preceptor Interaction & Effective teachers who are available and willing to demonstrate (Preceptors readily available) \\
\hline
\end{tabular}

McMaster trainees responding were higher and Toronto trainees lower than the population surveyed [3,13].

Factor analysis revealed 7 preceptor factors and 6 site factors valued in the ambulatory setting [3]. These are defined in Table 1 with sample scale items. The factor structure and reliability of the Workplace Learning questionnaire were confirmed for the population [14]. Scales are presented in italics in the following discussion to emphasize that the associations are between scale scores.

Higher scores on the Deep approach to learning scale were associated with placing higher value on all of the preceptor and site characteristics valued by clerks and residents (table 2). Preceptor Direction was more strongly predicted by Surface Rational and Surface Disorganized scales than by the Deep scale (table 2).

The Deep scale predicted valued site characteristics of Office Management, Patient Logistics, Objectives and Preceptor Interaction (table 3). The Surface Rational scale predicted valuing Learning Resources and Clinic Set-up. The Surface Disorganized scale weakly negatively predicted Patient Logistics and positively Learning Resources.

Climate factors were not strongly predictive (tables 2 and 3). Role Modeling and Patient Logistics were predicted by Supportive Receptive climate. Perception of heavy workload (Workload) predicted valuing Direction, Clinic Set-up and Objectives. Perception of Choice/Independence in the workplace weakly and negatively predicted valuing Feedback.

\section{Discussion}

In this analysis of a multi-site, multi-level and multi-specialty study we found that higher scores on the Deep approach to learning scale predicted all of the learners' preferred preceptor characteristics, supporting the implementation of these in the ambulatory setting. The Deep approach to learning was in general more strongly associated with the valued preceptor factors than the valued site characteristics except for Direction.

Giving direction was more valued by learners with higher scores on the Surface Rational and Surface Disorganized scales. One interpretation may be the need for these learners to know what is expected of them. Although struggling learners may require this support, too close direction may interfere with the development of independence and lifelong learning skills. We have found that physicians who take a predominantly deep approach to learning are selfmotivated for learning and prefer independent methods for continuing medical education [12]. In contrast, the physicians who score highly on surface approaches to learning are motivated by extrinsic factors such as regulating authorities or fear of a lawsuit [12]. As Samuel Johnson wrote, "when a man knows he is to be hanged in a fortnight, it concentrates his mind wonderfully" but it is likely a costly and ineffective approach for independent lifelong learning. Relying too heavily on "what is on the exam" or what the preceptor wants does not allow for selfassessment and may lead to less effective outcomes.

Learners' approaches to learning are not one or another, but more or less of the approaches measured and will vary 
Table 2: Prediction of valued preceptor characteristics by approaches to learning and perception of workplace climate. ( $\beta$ coefficients)

\begin{tabular}{lccccccc}
\hline & $\begin{array}{c}\text { Professional } \\
\text { Role Modelling }\end{array}$ & Teaching & $\begin{array}{c}\text { Learning } \\
\text { Climate }\end{array}$ & Feedback & Direction & $\begin{array}{c}\text { Patient } \\
\text { Presence }\end{array}$ & $\begin{array}{c}\text { Health Care } \\
\text { System } \\
\text { Interaction }\end{array}$ \\
\hline Deep & $.234^{* *}$ & $.224^{* *}$ & $.207^{* *}$ & $.155^{* *}$ & $.076^{*}$ & $.091^{* *}$ \\
Surface Rational & $.077^{*}$ & $.179^{* *}$ & $.101^{* *}$ & $.111^{* *}$ & $.252^{* *}$ & $.118^{* *}$ & $.180^{* *}$ \\
Surface Disorganized & .064 & .013 & .035 & .015 & $.154^{* *}$ & .072 & .048 \\
Choice/Independence & -.046 & -.056 & .016 & $-.095^{*}$ & .023 & .066 & .016 \\
Workload & $.094^{* *}$ & .043 & $.088^{*}$ & .010 & $.070^{*}$ & .012 & .043 \\
Supportive Receptive & $.135^{* *}$ & .054 & .065 & .025 & -.008 & -.042 & .058 \\
Adjusted R2 & .094 & .092 & .079 & .036 & .132 & .036 & .061 \\
\hline
\end{tabular}

$*_{p}<.01, *^{*} p<.001$

with the context. In this study we did not find a significant influence in the models of the perception of the workplace climate on valued site or preceptor characteristics. We did confirm earlier finding that the approach to learning and perception of the workplace climate are associated $[6,12,13]$. Thus, it may be that when the learning climate is stressful, learners may shift from a preferred approach to learning, to one that helps them survive. The surface rational approach may be necessary in a busy clinic when there is little time for reflection. In this setting, the organization or clinic characteristics may become more salient to the learner.

McManus has shown that approaches to learning are predicted by personality and learning styles [15]. Personality traits tend to be stable but learning styles and approaches to learning can be modified by formal education [16-18]. It may be important to encourage the struggling or dependent learner to become more self-directed. As workload is associated with surface approaches to learning, the challenge in the ambulatory setting will be to pace the patient volume and variety of problems to provide adequate time for learning with the aim of supporting deeper approaches to learning.

Dolmans and colleagues used path analysis to determine the importance of some variables influencing the effectiveness of student rotations at out-patient clinics in one medical school [19]. Input variables, such as organizational quality, number of students contemporaneously involved and available space, and process variables, such as patient mix and supervision, were analyzed in relation to one output variable: the students' evaluation of the effectiveness of the rotation. Supervision was the most important influence on the student's perception of the effectiveness of the rotation. This finding is consistent with the stronger prediction of valued preceptor characteristics than site characteristics in our study.
Dolman's model focused on organizational variables and did not take into account differences in the students and how they learn. Biggs' model suggests that the student's approaches to learning are input variables that interact with the organizational variables to affect what students do to learn [8]. The trend for site characteristics to be more strongly predicted by the Surface Rational approach to learning reflects the desire for good organization by some learners. Our findings extend Dolman's model to help teachers understand the different values placed on site and preceptor characteristics in the ambulatory setting by learners employing different approaches to learning.

This study has several limitations. First, the predictive power of approach to learning on valued site characteristics is small, suggesting that other factors we have not measured, such as personality, may be important in determining characteristics valued by the learners [17]. Ability, expectations and prior knowledge may also be important. Secondly, approaches to learning are influenced by many factors and do not represent an outcome of the learning experience. Thirdly, deep learners may be effective learners in any setting. It is not know if adapting the setting or changing preceptor behaviours to those valued by these learners will be helpful for learners who take less effective approaches. Further work is required to assess whether changes in preceptor or site characteristics affect learning outcomes or shift the learner's approach to learning.

\section{Conclusion}

Most site and preceptor characteristics valued by clerks and residents were predicted by their Deep approach to learning scores validating these preferences. Preceptor characteristics are likely more important for learning than site characteristics. Some characteristics reflecting the need for good organization and clear direction are predicted by learners' scores on less effective, surface approaches to learning. These findings provide insight on the needs of more vulnerable learners. 
Table 3: Prediction of valued site characteristics by approaches to learning and perception of workplace climate. ( $\beta$ coefficients)

\begin{tabular}{|c|c|c|c|c|c|c|}
\hline & $\begin{array}{c}\text { Office } \\
\text { Management }\end{array}$ & Patient logistics & Objectives & $\begin{array}{l}\text { Learning } \\
\text { Resources }\end{array}$ & Clinic Setup & $\begin{array}{l}\text { Preceptor } \\
\text { Interaction }\end{array}$ \\
\hline Deep & $.113 * *$ & $.119 * *$ & $.161^{* *}$ & .068 & $.078^{*}$ & $.086 * *$ \\
\hline Surface Rational & $.128 * *$ & $.080 *$ & $.190 * *$ & $.090 * *$ & $.197 * *$ & $.087^{* *}$ \\
\hline Surface Disorganized & .031 & $-.082 *$ & -.004 & $.088^{*}$ & .070 & .010 \\
\hline Choice/Independence & .047 & -.017 & .003 & .020 & .076 & -.064 \\
\hline Workload & .071 & .056 & $.074 *$ & .051 & $.081^{* * *}$ & .068 \\
\hline Supportive Receptive & .065 & $.118 * *$ & -.010 & .064 & .023 & .050 \\
\hline Adjusted $\mathrm{R}^{2}$ & .054 & .044 & .076 & .033 & .083 & .021 \\
\hline
\end{tabular}

$*_{\mathrm{p}}<.01,{ }^{*} \mathrm{p}<.001$

\section{Competing interests}

The author(s) declare that they have no competing interests.

\section{Authors' contributions}

All authors participated in the conceptual planning and design of the study. DD and JK provided the statistical analysis and data interpretation. DD prepared the manuscript and all authors participated in interpretation and manuscript revision.

\section{Acknowledgements}

The project was supported by a Research in Medical Education grant from the Canadian Institute of Health Research and Association of Canadian Medical Colleges. The authors would like to thank Jason Schmelzle for careful data entry and Rachelle Sequin for project management.

\section{References}

I. Irby DM: Teaching and Learning in Ambulatory Care Settings: A Thematic Review of the Literature. Acad Med 1995, 70(10):898-93I.

2. Lesky LG, Hershman WY: Practical Approaches to a Major Educational Challenge. Arch Intern Med 1995, 1 55:897-904

3. Schultz KW, Kirby JR, Delva MD, Godwin M, Verma S, Birtwistle RV, Knapper C: Medical Student's and Resident's Preferred Site Characteristics and Preceptor Behaviours for Learning in the Ambulatory Setting: A Cross-Sectional Survey. BMC Med Educ 2004, 4(I): I 2. (Aug 6, 2004)

4. Kember D, Biggs J, Leung DY: Examining the multidimensionality of approaches to learning through the development of a revised version of the Learning Process Questionnaire. $\mathrm{Br}$ J Educ Psychol 2004, 74:26I-79.

5. Bowen J, Irby DM: Assessing Quality and Costs of Education in the Ambulatory Setting: A Review of the Literature. Acad Med 2002, 77:621-680.

6. Kirby JR, Knapper CK, Evans CJ, Carty AE, Gadula C: Approaches to learning at work and workplace climate. Int J Training Dev 2003, 7:31-52

7. Vu NV, van der Vleuten CPM, Lacombe G: Medical students' learning processes: A comparative and longitudinal study. Acad Med 1998:s25-s27.

8. Biggs JB: Student approaches to learning and studying Melbourne:Australian Council for Educational Research; 1987.

9. Entwistle NJ, Tait H: Approaches to learning, evaluations of teaching, and preferences for contrasting academic environments. Higher Educ 1990, 19:169-194.

10. Entwistle NJ: Approaches to learning and perceptions of the learning environment. Higher Educ 1991, 22:201-204.
II. Ramsden P: Context and strategy. Situational influences on learning. In Learning Styles and Strategies Edited by: Schmeck RR. New York: Plenum Press; 1986:159-184.

12. Delva MD, Kirby J, Knapper C, Birtwhistle RV: Postal survey of approaches to learning among Ontario physicians: Implications for continuing medical education. $B M J$ 2002, 325: 1218 .

13. Delva MD, Kirby J, Schultz K, Godwin M: Assessing the Relationship of Learning Approaches to Workplace Climate in Clerkship and Residency. Acad Med 2004, 79: I I 20- I I 26.

14. Kirby JR, Delva MD, Knapper C, Birtwistle RV: Development of the Approaches to Work and Workplace Climate Questionnaires for Physicians. Eval Health Prof 2003, 26:104-21.

15. McManus IC, Keeling A, Paice E: Stress, burnout and doctors' attitudes to work are determined by personality and learning style: A twelve year longitudinal study of UK medical graduates. BMC Medicine 2004, 2:29.

16. Biggs JB: Teaching for quality learning at university Milton Keynes: SRHE Open University Press; 2003.

17. McManus IC, Richards P, Winder BC: Intercalated degrees, learning styles, and career preferences: prospective longitudinal study of UK medical students. Brit Med J 1999, 3 1 9:542-546.

18. Biggs JB, Rihn BA: The effects of intervention on deep and surface approaches to learning. In Cognitive strategies and educational performance Edited by: Kirby JR. Orlando FL: Academic Press; 1984:279-293.

19. Dolmans DH, Wolfhagen HA, Essed GG, Scherpbier AJ, Van Der Vleuten CP: Students' perceptions of relationships between some educational variables in the out-patient setting. Med Educ 2002, 36:735-4I.

\section{Pre-publication history}

The pre-publication history for this paper can be accessed here:

http://www.biomedcentral.com/1472-6920/5/35/prepub 